\title{
Compósitos de cimento Portland com adição de nanotubos de carbono (NTC): Propriedades no estado fresco e resistência à compressão
}

\author{
Portland cement composites with \\ carbon nanotubes (CNT) addition: Properties in \\ freshly state and compressive strength
}

\author{
Marcelo Henrique Farias de Medeiros ${ }^{1}$, Francielle Dranka ${ }^{2}$, \\ Alécio Júnior Mattana ${ }^{2}$, Marienne do Rocio de Mello Maron da Costa ${ }^{2}$
}

\author{
${ }^{1}$ Av. Governador Agamenon Magalhães, 239 - Ap. 102A - Torre I - Cristo Rei, Curitiba, PR CEP: 80050-510 \\ e-mail: medeiros.ufpr@gmail.com \\ ${ }^{2}$ Endereço dos outros autores: \\ e-mail: f.dranka@hotmail.com, alecio.mattana@ifpr.edu.br, mariennemaron@gmail.com
}

\begin{abstract}
RESUMO
Alguns estudos têm sido desenvolvidos sobre a adição de nanotubos de carbono (NTCs) em compósitos cimentícios e indicam melhorias nas propriedades mecânicas, como aumento da resistência à compressão, à tração e diminuição da porosidade. Com base nessas possíveis melhorias, essa pesquisa foi realizada para analisar a influência dos NTCs na resistência à compressão e fluidez de compósitos de cimento Portland que possam ser usados para reabilitação de estruturas de concreto. Desse modo, foram realizados ensaios de resistência à compressão, squeeze flow, flow table, funil de Marsh e miniabatimento. Foram fixadas uma argamassa e uma pasta de referência (sem adição de nanotubos de carbono), que foram replicadas com mesmo traço e a incorporação de 5 teores de NTCs em relação à massa de cimento: $0,1 \%, 0,2 \%, 0,3 \%, 0,4 \%$ e $0,5 \%$. Estes teores foram escolhidos de modo a abranger a faixa de teores mais usadas nas pesquisas sobre NTCs adicionados aos compósitos de cimento Portland. Com relação aos ensaios de medição de fluidez, foi constatado que quanto maior o teor de NTC, mais consistente o compósito cimentício, com indícios de que os teores menores ou iguais a $0,3 \%$ são mais adequados para manter a fluidez do compósito de cimento Portland. No caso da resistência à compressão, os resultados indicam que a adição de $0,40 \%$ de nanotubos de carbono tende a elevar a resistência em $27 \%$. Por outro lado, a adição de $0,5 \%$ de NTC deixou o compósito tão consistente que dificultou a moldagem e a elevação da resistência foi nula comparada a série de referência.
\end{abstract}

Palavras-chave: Nanotubos de carbono, argamassa de reparo, cimento Portland, consistência, fluidez.

\begin{abstract}
Currently there are some studies on the addition of carbon nanotubes (CNTs) in cement composites. These studies indicate enhancements in the mechanical properties, such as increase in compressive strength, tensile strength and durability, and porosity decrease. Based on these possible improvements, this research was conducted to analyze the influence of CNTs on the compressive strength of mortar for rehabilitation of concrete structures, as well as in their consistency. Compressive strength, squeeze flow, flow table, marsh funnel and mini-slump tests were carried. A control mortar and paste were used (without carbon nanotubes added), which was replicated with the same mix proportioning and the incorporation of 5 levels of CNTs related to the cement mass: $0.1 \%, 0.2 \%, 0.3 \%, 0.4 \%$ to $0.5 \%$. These concentrations were chosen to cover the commonly range used in researches about Portland cement composites with CNTs addition. Regarding the tests for measuring the fluidity of mortars and pastes, it was found that the higher the percentage of CNT, more consistent the cement Portland composite became, with evidence that smaller or equal to $0.3 \%$ levels of NTCs are more adequate to maintain the fluidity of the Portland cement composite. Results indicate that the addition of $0.40 \%$ of carbon nanotubes increases the compressive strength by $27 \%$. On the other hand, addition of $0.5 \%$ of CNT became the Portland cement composite very consistent, making difficult the molding process, so that the increase in compressive strength was zero compared to the control mortar.
\end{abstract}


Keywords: Carbon Nanotubes, repair mortar, Portland cement, consistency, fluidity.

\section{INTRODUÇÃO}

Com o grande crescimento da construção civil, os estudos relacionados aos novos materiais são necessários e estão em amplo desenvolvimento. Dentro deste contexto, um dos tópicos que mais está chamando a atenção é a categoria de concretos de terceira geração, classificação dada por Sanchez e Sobolov [1]. Segundo os pesquisadores, o concreto pode ser classificado de acordo com as dimensões dos agregados ou adições usadas, com isso, os concretos com adição de nanomateriais se enquadram na terceira geração, como mostra a Figura 1 .

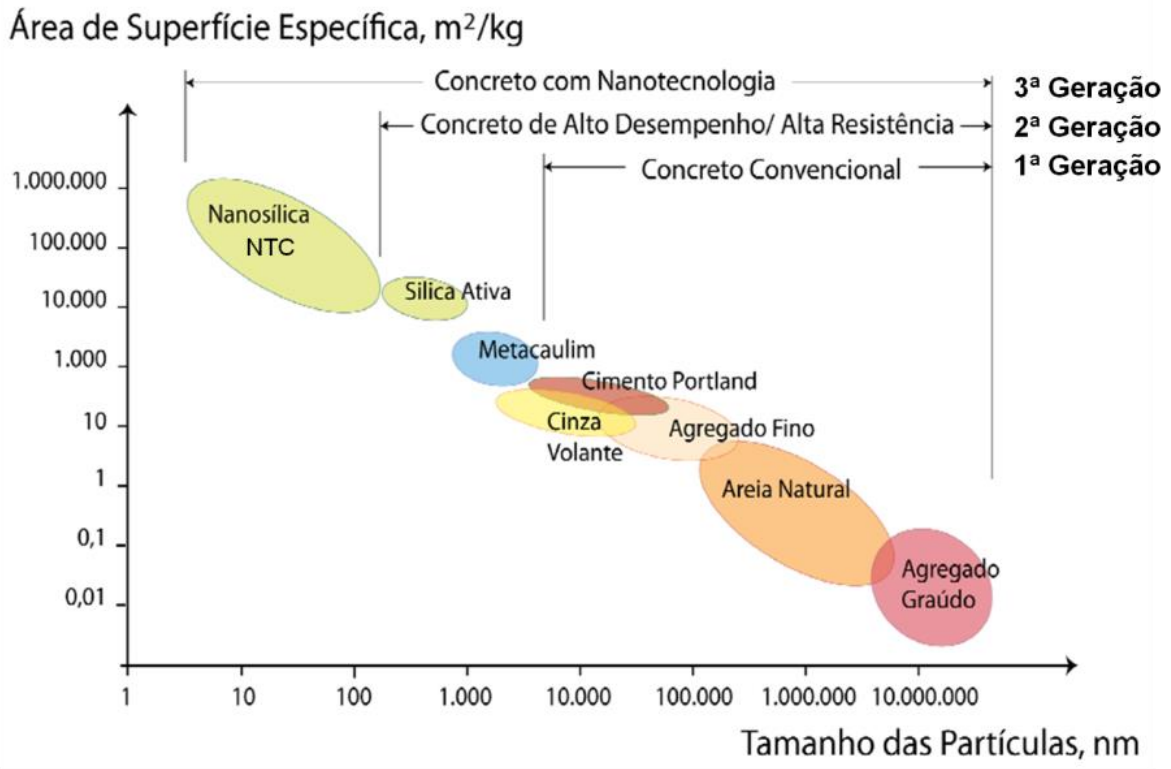

Figura1: Área de superfície específica e tamanho das partículas relacionadas ao tipo de concreto [2] adaptado por [1]].

Considerando a área de compósitos de cimento Portland, o foco deste trabalho está voltado para as argamassas de reparo para estruturas de concreto armado. Neste campo, o melhoramento da argamassa é fator primordial de desenvolvimento da indústria de materiais especiais para Construção Civil, sendo comum a otimização do material com produtos adversos, ainda que de maior custo, uma vez que as argamassas de reparo são produtos reconhecidamente mais caros devido a sua necessidade de dosagem e controle tecnológico voltado para a redução da possibilidade de falha dos serviços de reabilitação das estruturas de concreto armado. Dentro deste pano de fundo, as argamassas de reparo têm sido pesquisadas com o foco em temas diversos. Por exemplo: Atzeni et al. [3] estudaram a influência dos ciclos de gelo e degelo no mecanismo de falha de reparos localizados; Hassan et al. [4] e Mirza et al. [5] estudaram a eficiência dos reparos de cimento Portland expostos a clima quente e seco e em clima frio, respectivamente; Medeiros et al. [6], Ramli et al. [7] e $\mathrm{Ma}, \mathrm{Li}$ [8] pesquisaram o melhoramento das argamassas de reparo usando adição de polímeros; Medeiros [9] e Ramli, Tabassi [10] abordaram a influência das condições de cura nas propriedades das argamassas de reparo; Ribeiro et al. [11] focaram na avaliação da interação eletroquímica entre o aço e a argamassa em áreas reparadas.

O trabalho deste artigo está focado em investigar a possibilidade de usar nanotubos de carbono (NTC) para o melhoramento de materiais de reparo à base de cimento Portland. Neste caso, o estudo está concentrado no efeito dos NTCs na resistência à compressão e propriedades no estado fresco da argamassa, que influenciam diretamente a aplicabilidade das mesmas na prática de execução de serviços de reparo em campo.

\section{REVISÃO BIBLIOGRÁFICA}

\subsection{Nanotubos de carbono em compósitos de cimento Portland}

Entre os nanomateriais de maior destaque na atualidade estão a nanosílica (NS) e o nanotubo de carbono (NTC). Segundo Marcondes [12], o desenvolvimento dessa nova tecnologia pode possibilitar melhorias em concretos e argamassas. De acordo com Melo [13], as melhorias em diversas propriedades dos concretos com adição de nanomateriais se devem ao minúsculo tamanho das partículas que contribuem para o preenchimen- 
to de vazios, além do fato que eles têm o potencial para aumentar a resistência, ou retardar a propagação de fissuras em compósitos de cimento e agem como agentes de nucleação de reações químicas de hidratação do cimento Portland.

O estudo de Chaipanich et al. [14] comprovou que a adição de nanotubos de carbono aumentou a resistência de cimentos compostos com cinzas volantes. Em sua pesquisa, foram analisados os teores de 0,5\% e $1 \%$ de NTCs em relação à massa de cimento, sendo que o segundo com $20 \%$ de cinza volante apresentou $10 \%$ de aumento na resistência à compressão. De acordo com Chaipanich et al. [14], a análise com microscópico eletrônico de varredura indicou uma boa interação entre partículas de cinzas volante e nanotubos de carbono.

Melo [13] encontrou um aumento da resistência à compressão e à tração em matrizes de cimento Portland com adição de NTCs. A pesquisa também provou uma redução do tamanho médio dos poros, o que pode aumentar a durabilidade de estruturas de concreto, já que diâmetros menores dificultam a circulação de agentes agressivos dentro do concreto devido à redução da interconexão da rede de poros. No trabalho de Melo [13], o teor de 0,3\% de nanotubos apresentou a maior capacidade de elevação da resistência.

Makar et al. [15] defendem que o aumento na durabilidade de concretos e argamassas com adição de NTCs se deve as pontes de aderência que se formam na microestrutura da pasta (Figura 2). Elas controlam as fissuras geradas na matriz cimentícia e, consequentemente, promovem maiores resistências e diminuição na porosidade.

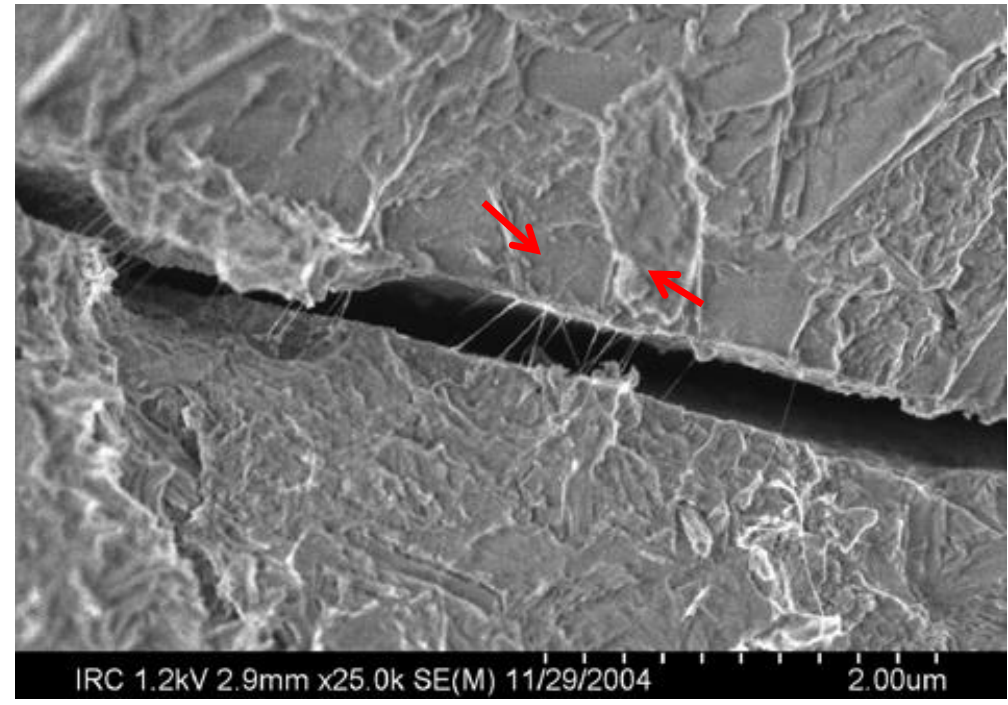

Figura 2: Microfissura na pasta de cimento com adição de NTCs agindo como pontes de aderência [15].

Li et al. [16] também citam uma ponte de ligação entre o cimento hidratado e os nanomateriais em uma das justificativas do aumento da resistência em argamassas que tiveram a incorporação de nanotubos de carbono. Outras explicações implicam no fato de que nanopartículas preenchem os vazios da pasta de cimento e impedem a formação de alguns cristais de baixa resistência, com isso tem-se o aumento da resistência. Também foi relatado, nesse estudo, o aumento da temperatura em concretos com adição de nanosílica, o que demonstra a alta reatividade do material.

Marcondes [12] registrou um aumento de até 36\% na resistência à compressão para concretos convencionais com adição de 0,3\% de NTC, uso de cimento Portland CP V-ARI e relação água/cimento igual a 0,55. Também foi verificada a redução da absorção por imersão e elevação da sucção capilar, devido ao refinamento dos poros, proporcionado pela adição de nanotubos de carbono. $\mathrm{O}$ autor destaca a atenção que precisa ser dedicada à trabalhabilidade, pois no ensaio de tronco de cone os resultados apresentaram uma diminuição do abatimento devido à influência dos NTCs.

Apesar de serem usados em diversas áreas, os nanotubos de carbono ainda apresentam alto custo, o que pode ser um empecilho para a utilização desse material em compósitos cimentícios. Mas acredita-se que com o aumento da demanda e com a possibilidade de sintetizar os NTCs na fabricação do clínquer, o que está sendo estudado na Universidade Federal de Minas Gerais (UFMG), o material irá se tornar mais acessível. Desse modo, embora o custo do material seja um aspecto negativo na atualidade, a tendência é que este inconveniente seja superado ao longo do tempo. 


\subsection{Dispersão dos Nanotubos de carbono}

Segundo Koshio et al. [17], a dispersão dos nanotubos de carbono pela utilização da energia ultrassônica é eficaz, o que foi comprovado pelos pesquisadores Konsta et al. [18], que também utilizaram um surfactante (agente de atividade superficial).

Em sua pesquisa, Marcondes [12] realizou um experimento sobre a dispersão de NTCs em meio aquoso com aplicação de ultrassom. Os resultados mostraram que o tempo de dispersão entre 40 e 60 minutos é ideal, porque não causa decantação dos nanotubos de carbono após 24 horas de repouso.

Mendoza et al. [19] mostraram que, para sistemas NTCs/Superplastificante/água, quanto maior for a energia ultrassônica, maior será a dispersão obtida. Além disso, os autores demonstraram que o aditivo superplastificante ajuda a manter os NTCs dispersos após 24 horas (Figura 3).
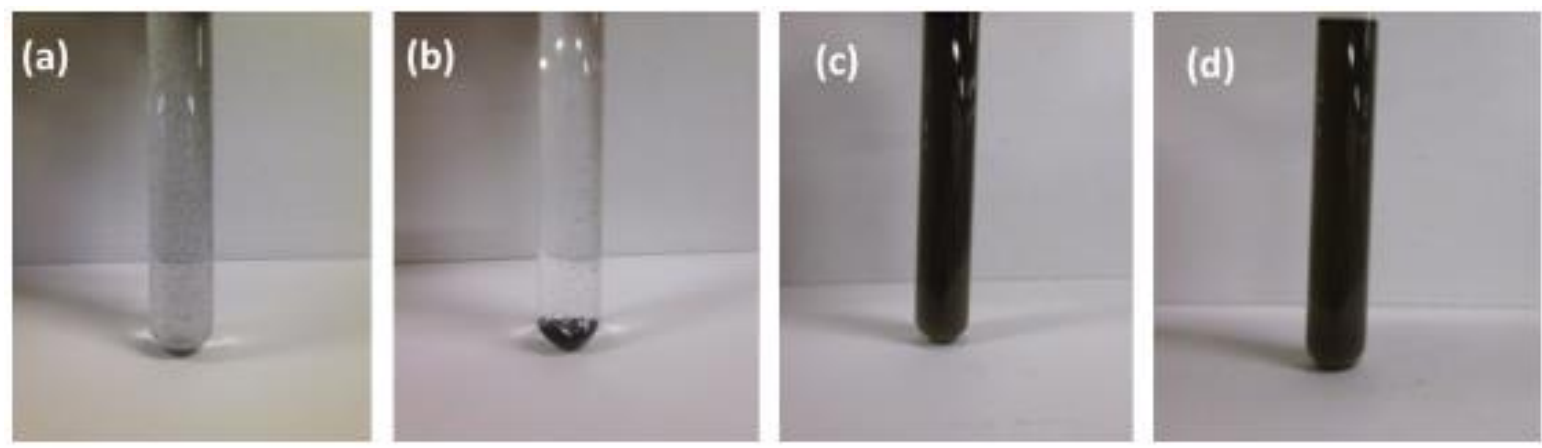

Figura 3: Estabilidade de dispersões de NTCs/água com 0h (a) e após 24h (b), e NTCs/SP/água com 0h (c) e após 24h (d) [19].

\section{MATERIAIS E MÉTODOS}

Este trabalho apresenta como variável de estudo o teor de nanotubos de carbono (NTC) que foi variado em $0 \%, 0,1 \%, 0,2 \%, 0,3 \%, 0,4 \%$ e $0,5 \%$ em relação à massa de cimento. Estes teores foram escolhidos de modo a abranger a faixa de teores mais usadas nas pesquisas sobre NTCs adicionados aos compósitos de cimento Portland.

Como variáveis de resposta do estudo, pode-se listar as que estão a seguir: squeeze flow, espalhamento no flow table, tempo de escoamento no cone de Marsh, espalhamento pelo miniabatimento e resistência à compressão. Como o foco principal deste trabalho foi de caracterizar o estado fluído dos compósitos de cimento Portland com e sem NTC, optou-se por empregar um conjunto de técnicas associadas. Esta prática faz com que sejam disponibilizados resultados de ensaios mais completos, como o squeeze flow, como de técnicas menos precisas e mais acessíveis nos laboratórios de pesquisas na área argamassas e pastas de cimento Portland. Além disso, foram usadas duas técnicas que caracterizam pastas (interação entre o cimento, aditivo superplastificante, NTC e água) e duas outras técnicas que possibilitaram o estudo da influência dos NTCs em argamassas.

Os ensaios de squeeze flow e espalhamento no flow table apresentam a característica de testar as argamassas em condições padronizadas de esforço aplicado, que pode ser relacionado ao comportamento vinculado a atividade de aplicação da argamassa. Na área de reparo localizado em estruturas de concreto armado, a aplicação pode ser feita manualmente (material com consistência semelhante a uma massa de modelar) ou na forma de material auto adensável, aplicado com a instalação de formas e aplicado por gravidade, se assemelhando mais ao caso dos ensaios de cone de Marsh e miniabatimento. Apesar de estes ensaios não simularem aplicações práticas, é interessante usar os ensaios semelhantes a certas condições de aplicação do material a ser testado.

\subsection{Materiais}

A seguir é apresentada toda a caracterização do material utilizado na parte experimental da pesquisa.

\section{Cimento}

Para a confecção da argamassa foi utilizado o cimento CP V - ARI da empresa Cia. de Cimento Itambé, cidade de Balsa Nova. Esse tipo de cimento foi escolhido devido ao foco da pesquisa que é argamassa para reabilitação de estruturas, onde é necessária alta resistência inicial.

Outro motivo para a escolha desse material foi pelo fato de não possuir cinza pozolânica e conter mais clínquer em sua composição. Com isso, evita-se a interação dos compostos pozolânicos desconhecidos em 
termos de percentual no cimento Portland e pode-se focar na influência entre o cimento puro com percentual conhecido de sílica ativa e os NTCs, foco deste estudo.

O material tem os resultados mecânicos e caracterização química descrita na Tabela 1.

Tabela 1: Caracterização do CP V - ARI (fonte: Cia. de cimento Itambé).

\begin{tabular}{|c|c|c|c|c|c|c|c|c|c|c|c|}
\hline \multicolumn{12}{|c|}{ Ensaios Químicos } \\
\hline \multirow[t]{2}{*}{ Cimento } & $\mathrm{Al}_{2} \mathrm{O}_{3}$ & $\mathrm{SiO}_{2}$ & $\mathrm{Fe}_{2} \mathrm{O}_{3}$ & $\mathrm{CaO}$ & $\mathrm{MgO}$ & $\mathrm{SO}_{3}$ & $\begin{array}{l}\text { Perda } \\
\text { fogo }\end{array}$ & $\begin{array}{l}\mathrm{CaO} \\
\text { livre }\end{array}$ & \multicolumn{2}{|c|}{$\begin{array}{c}\text { Resid. } \\
\text { Insol }\end{array}$} & $\begin{array}{l}\text { Equiv. } \\
\text { Alcal }\end{array}$ \\
\hline & $\%$ & $\%$ & $\%$ & $\%$ & $\%$ & $\%$ & $\%$ & $\%$ & \multicolumn{2}{|c|}{$\%$} & $\%$ \\
\hline CP V-ARI & 4,47 & 19,19 & 2,80 & 60,34 & 5,05 & 2,80 & 2,91 & 1,67 & & 79 & 0,72 \\
\hline \multicolumn{12}{|c|}{ Ensaios Físicos } \\
\hline \multirow[t]{2}{*}{ Cimento } & \multicolumn{2}{|c|}{ Inicio de pega } & $\begin{array}{c}\text { Fim de } \\
\text { pega }\end{array}$ & $\begin{array}{c}\text { Massa } \\
\text { esp. }\end{array}$ & Blaine & \#200 & 0 \#325 & $\begin{array}{c}1 \\
\text { dia }\end{array}$ & $\begin{array}{c}3 \\
\text { dias }\end{array}$ & $\begin{array}{c}7 \\
\text { dias }\end{array}$ & $\begin{array}{c}28 \\
\text { dias }\end{array}$ \\
\hline & \multicolumn{2}{|c|}{$\mathrm{h}: \min$} & $\mathrm{h}: \min$ & $\mathrm{g} / \mathrm{cm}^{3}$ & $\mathrm{~cm}^{2} / \mathrm{g}$ & $\%$ & $\%$ & $\mathrm{MPa}$ & $\mathrm{MPa}$ & $\mathrm{MPa}$ & $\mathrm{MPa}$ \\
\hline$\overline{\mathrm{CP} V-\mathrm{ARI}}$ & \multicolumn{2}{|c|}{$02: 28$} & 03:03 & 3,12 & 4.213 & $\overline{0,4}$ & 2,75 & 22,0 & 35,3 & 41,3 & 50,3 \\
\hline
\end{tabular}

Sílica Ativa

Optou-se pela utilização da sílica ativa na argamassa porque este é um material que provoca melhorias em algumas propriedades dos compósitos cimentícios, como diminuição da porosidade, aumento da aderência, redução do calor de hidratação, aumento da resistência à compressão e à tração.

A sílica ativa usada foi da marca Tecnosil. Suas características físicas e químicas estão apresentadas na Tabela 2 e a análise química da amostra usada no trabalho está na Tabela 3.

Tabela 2: Características físicas e químicas da sílica ativa (fonte: Tecnosil).

\begin{tabular}{c|c}
\hline Caracteristicas & Valor \\
\hline Massa específica & $2.200 \mathrm{Kg} / \mathrm{m}^{3}$ \\
\hline Teor de $\mathrm{SiO}_{2}$ & $>90 \%$ \\
\hline Superfície específica (B.E.T.) & $19 \mathrm{~m}^{2} / \mathrm{g}$ \\
\hline Formato da partícula & Esférico \\
\hline Diâmetro médio da partícula & $0,20 \mu \mathrm{m}$ \\
\hline
\end{tabular}

Tabela 3: Análise química da sílica ativa (fonte: Tecnosil).

\begin{tabular}{|c|c|c|c|c|c|c|c|c|c|c|c|}
\hline \multicolumn{12}{|c|}{ Ensaios Químicos } \\
\hline$\% \mathrm{Fe}_{2} \mathrm{O}_{3}$ & $\% \mathrm{CaO}$ & $\% \mathrm{Al}_{2} \mathrm{O}_{3}$ & $\% \mathrm{MgO}$ & $\% \mathrm{Na}_{2} \mathrm{O}$ & $\% \mathrm{~K}_{2} \mathrm{O}$ & $\% \mathrm{SiO}_{2}$ & $\% \mathrm{H}_{2} \mathrm{O}$ & $\%$ LOI & $\% \mathrm{pH}$ & $\%$ B.H. & $\% 46 \mu \mathrm{m}$ \\
\hline 0,14 & 0,30 & 0,16 & 0,60 & 0,23 & 0,80 & 95,26 & 0,88 & 2,02 & 8,76 & 0,33 & 1,01 \\
\hline
\end{tabular}

Agregado Miúdo

O agregado miúdo é uma areia natural quartzosa proveniente de extração de leito de rio, que tem mas-

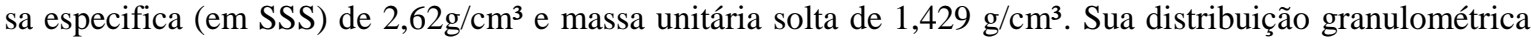
está apresentada na Tabela 4.

Tabela 4: Distribuição granulométrica da areia.

\begin{tabular}{c|c|c|c|c|c|c}
\hline \multirow{2}{*}{$\begin{array}{c}\text { Abertura da } \\
\text { malha das } \\
\text { peneiras (mm) }\end{array}$} & \multicolumn{2}{|c|}{ Massas retidas } & \multicolumn{3}{c}{$\begin{array}{c}\text { NBR 7211 [20] - Distribuição granulométrica } \\
\text { Porcentagens retidas acumuladas }\end{array}$} \\
\cline { 2 - 7 } & \multicolumn{2}{|c|}{$\begin{array}{c}\text { Média } \\
(\%)\end{array}$} & $\begin{array}{c}\text { Acumulada } \\
(\%)\end{array}$ & \multicolumn{2}{c}{ Limites inferiores } & \multicolumn{2}{c}{ Limites superiores } \\
\cline { 4 - 7 } & Zona útil & Zona ótima & Zona ótima & Zona útil \\
\hline 4,8 & 0 & 0 & 0 & 0 & 5 & 10 \\
\hline 2,4 & 0,57 & 0,57 & 0 & 10 & 20 & 25 \\
\hline 1,2 & 17,30 & 17,87 & 5 & 20 & 30 & 50 \\
\hline 0,6 & 24,75 & 42,62 & 15 & 35 & 55 & 70 \\
\hline 0,3 & 17,81 & 60,82 & 50 & 65 & 85 & 95 \\
\hline 0,15 & 30,38 & 90,81 & 85 & 90 & 95 & 100 \\
\hline Fundo & 9,19 & 100 & 100 & 100 & 100 & 100 \\
\hline
\end{tabular}


De acordo com a NBR 7211/2009 [20], especificação de agregado miúdo para concreto, a areia enquadra-se na zona útil, sendo adequada para uso em concretos e argamassas em termos de granulometria.

Aditivo Superplastificante

$\mathrm{O}$ aditivo superplastificante escolhido é composto por polímeros de éter carboxílico com $\mathrm{pH}$ de $5,5 \pm 1,0$. Como alguns pesquisadores evidenciaram que os NTCs apresentam maior tendência à dispersão em meios aquosos com aditivos superplastificantes $[\underline{16}, \underline{19}, \underline{21}, \underline{22}]$, optou-se pelo uso do aditivo superplastificante denominado MC -Power Flow 1102, da marca MC - Bauchemie, cujas características estão apresentadas na Tabela 5.

Mendoza et al. [19] apresentaram em seu estudo que o uso do aditivo superplastificante a base de éter policarboxilico deixou mais eficaz a dispersão dos NTCs á água, quando utilizado um equipamento de ultrassom. Isso se deve a interação aniônica entre as moléculas do superplastificante e as partículas de NTCs, que é hidrofóbica e sofre repulsão por forças eletrostáticas, evitando a aglomeração dos NTCs.

Tabela 5: Características do aditivo superplastificante (fonte: MC-Bauchemie).

\begin{tabular}{c|c|c}
\hline Características & Unidade & Valor \\
\hline Densidade & $\mathrm{kg} / \mathrm{dm}^{3}$ & 1,07 \\
\hline Dosagem recomendada & $\%$ em massa de cimento & $0,2-5$ \\
\hline Máximo teor de cloreto & $\%$ em massa & $<0,10$ \\
\hline Máximo teor de álcalis & $\%$ em massa & $<1,00$ \\
\hline
\end{tabular}

O fabricante indica esse aditivo para concretos de alto desempenho.

Nanotubos de carbono

O nanotubo de carbono (NTC) empregado neste trabalho foi produzido por uma empresa belga chamada Nanosyl S/A e foi fornecido em pó, sendo necessária a sua dispersão em água e aditivo antes do uso na confecção de compósitos de cimento Portland.

O tipo de NTC empregado é denominado comercialmente como NC 7000, trata-se de NTC de paredes múltiplas e seus dados técnicos estão presentes na Tabela 6 . Também se pode observar na Figura 4, a imagem deste nanotubo produzida por microscópico eletrônico de varredura.

Tabela 6: Caracterização dos NTCs belgas (fonte: Nanosyl S/A).

\begin{tabular}{c|c}
\hline Propriedade & Valor \\
\hline Diâmetro $(\mathrm{nm})$ & 9,5 \\
\hline Comprimento médio (Microns) & 1,5 \\
\hline Pureza de carbono $(\%)$ & 90 \\
\hline Óxido metálico $(\%)$ & 10 \\
\hline Área supeficial $\left(\mathrm{m}^{2} / \mathrm{g}\right)$ & 250 a 300 \\
\hline Densidade média $\left(\mathrm{g} / \mathrm{dm}^{3}\right)$ & 60 \\
\hline Grafite sintetizada $(\mathrm{NTC})(\%)$ & 90 \\
\hline
\end{tabular}




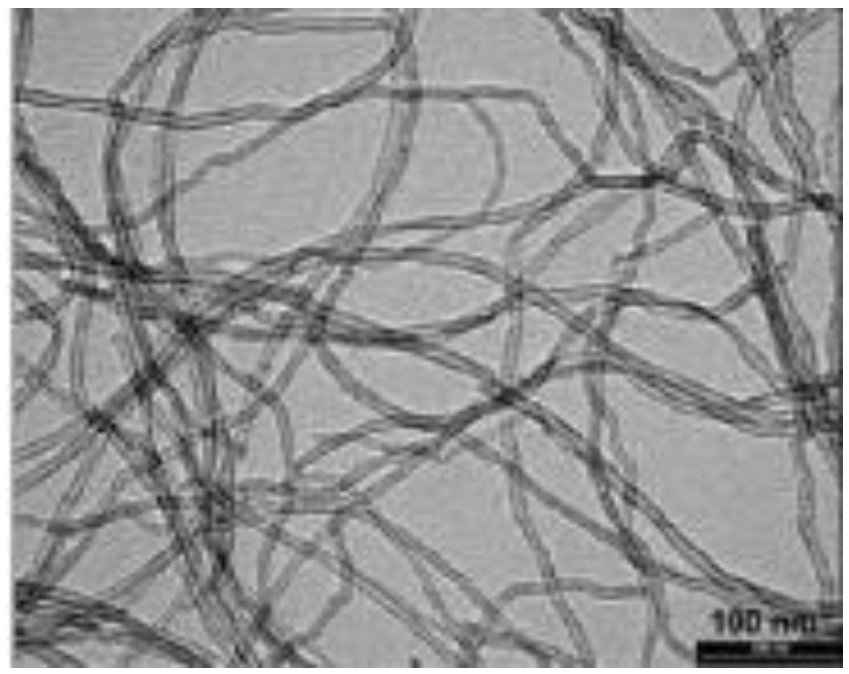

Figura 4: Imagem em MEV dos nanotubos de carbono empregados (fonte: Nanosyl S/A).

\subsection{Dispersão dos NTCs}

A pesagem dos NTCs para essa pesquisa foi realizada em uma balança tipo capela (com precisão de 0,0001 g) para evitar influencias do ambiente, já que a densidade deste material é pequena $\left(60 \mathrm{~g} / \mathrm{dm}^{3}\right)$. Os NTCs foram misturados à água e ao aditivo, como se pode observar nas etapas 2 e 3 da Figura 5, que ilustra como a adição de aditivo superplastificante auxilia na dispersão dos NTCs na água. O teor de superplastificante nas pastas e argamassas foi de $2 \%$ em relação à massa de cimento e não variou em função do aumento do teor de NTCs.

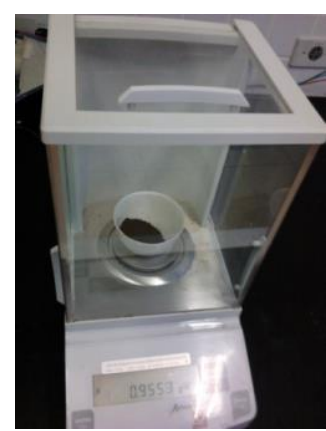

1. Pesagem dos NTCs

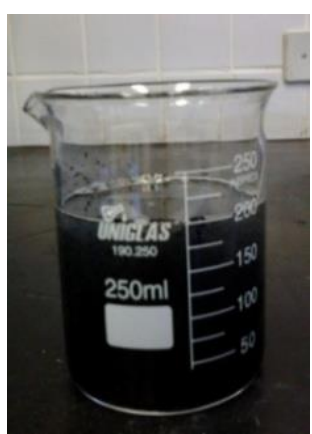

3. Adição do aditivo superplastificante

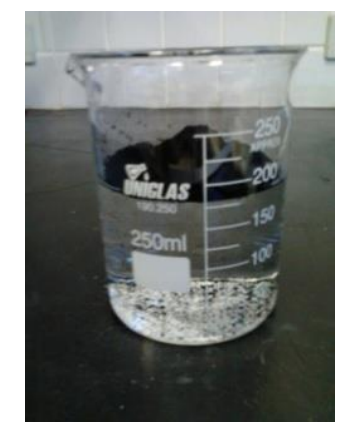

2. Adição dos NTCs à água

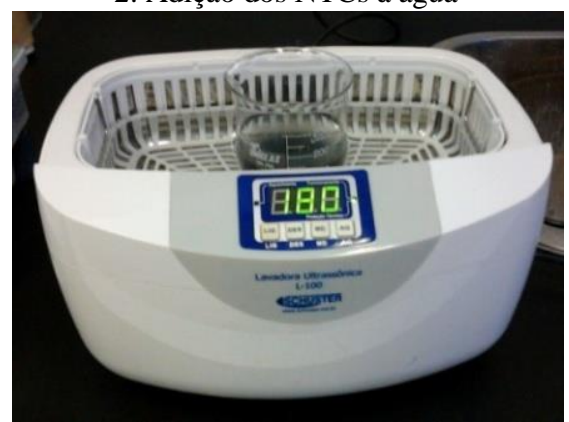

4. Dispersão na lavadora ultrassônica

Figura 5: Procedimento utilizado para a realização da dispersão de nanotubos de carbono.

Para melhorar ainda mais a dispersão, foi utilizada a lavadora ultrassônica L-100 da marca Schuster com uma frequência de $60 \mathrm{~Hz}$ e potência de $160 \mathrm{~W}$, equipamento observado na etapa 4 da Figura 5 . O processo de aplicação das ondas ultrassônicas teve duração de 50 minutos e a solução foi utilizada em menos de 24 horas depois da sonificação. 


\subsection{Confecção das argamassas e pastas}

A proporção de mistura da argamassa e pasta de referência é a que está representada na Tabela 7 e teve como base estudos na área de argamassas de reparo e incorporação de NTC em materiais de alto desempenho como os de Medeiros [9] e Henche [23]. O estudo de Medeiros [9] teve como foco o melhoramento de argamassas de reparo com o emprego de polímeros, como publicado em Medeiros et al. [6], e o de Henche [23] objetivou investigar a adição de NTCs nas argamassas de reparo. Ambos os trabalhos tiveram uma abordagem mais voltada às propriedades mecânicas. Os outros traços de argamassas e pastas empregados seguiram a mesma proporção da Tabela 7 com a diferença que tiveram o acréscimo dos teores de NTC escolhidos para serem estudados.

Tabela 7: Traço unitário em massa da argamassa e da pasta de referência.

\begin{tabular}{c|c|c}
\hline \multirow{2}{*}{ Material } & \multicolumn{2}{|c}{ Traço unitário em massa (kg) } \\
\cline { 2 - 3 } & Argamassa & Pasta \\
\hline Cimento & 1 & 1 \\
\hline Sílica ativa & 0,15 & 0,15 \\
\hline Agregado miúdo & 2 & --- \\
\hline a/c & 0,37 & 0,37 \\
\hline Aditivo superplastificante & 0,02 & 0,02 \\
\hline
\end{tabular}

O processo de mistura para a confecção das argamassas foi padronizado para evitar possíveis erros ou situações adversas que pudessem prejudicar a análise dos resultados. Todo processo foi dividido nos passos descritos a seguir.

- Mistura da parte em pó: após a pesagem de todo o material, os materiais secos (cimento, sílica ativa e areia) foram misturados na argamassadeira por cerca de 5 minutos a uma velocidade baixa;

- Á metade dos materiais secos, previamente misturados, foi acrescida a solução (água + aditivo + NTCs dispersos em ultrassom) e processada uma mistura em argamassadeira com velocidade lenta;

- Após a homogeneização da massa, a outra metade dos materiais secos foi adicionada aos poucos com a argamassadeira ligada. Toda a etapa de homogeneização da massa ocorreu entre 10 e 15 minutos.

Após a mistura, foi realizada a medida da temperatura da argamassa com termômetro de bastão (Figura 6), para verificar se a adição de NTCs aumenta a temperatura de compósitos cimentícios no estado fresco. Esta prática foi adotada pelo fato de em outros trabalhos ter-se notado manualmente que a argamassa com NTCs apresentava elevação de temperatura. Desse modo, no experimento desenvolvido neste trabalho foi realizada a medição da temperatura como indicado na Figura 6 para tentar comprovar este fato.

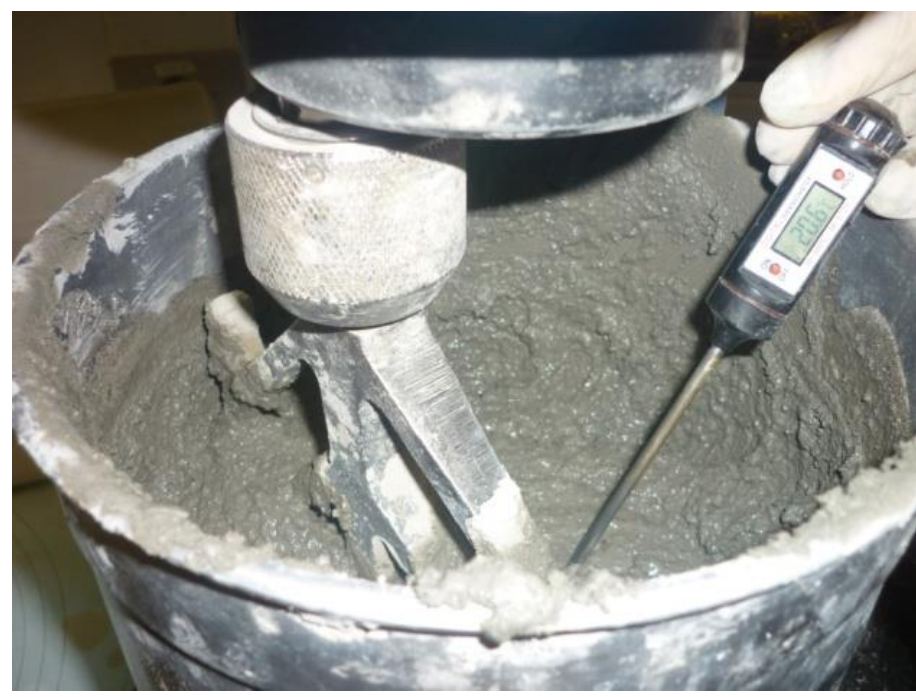

Figura 6: Medição da temperatura da argamassa após a mistura. 


\subsection{Ensaio de resistência à compressão}

O ensaio de resistência à compressão foi conduzido de acordo com a NBR 7215/1997 [24] com uma prensa da marca EMIC, com capacidade de carga de 30 t. Este ensaio foi realizado em corpos de prova cilíndricos com $\emptyset 50 x 100 \mathrm{~mm}$, e as rupturas ocorreram com 28 dias de idade em cura submersa. Foram moldados seis corpos de prova para cada caso de estudo e o teste de Tukey foi empregado para decidir se as médias são estatisticamente diferentes.

Antes da ruptura, os corpos de prova tiveram suas extremidades retificadas para garantir o paralelismo e planeza das suas faces de contato com a prensa, proporcionando assim a correta distribuição do carregamento aplicado pela prensa.

\subsection{Ensaio reológico de Squeeze Flow}

O ensaio consiste na medição do esforço necessário para a compressão uniaxial entre duas placas de uma amostra cilíndrica de $101 \mathrm{~mm}$ de diâmetro por $10 \mathrm{~mm}$ de altura. Esse ensaio é aplicado para argamassas de assentamento e revestimento de acordo com a NBR 15839/2010 [25]. Para esse ensaio foi utilizada a máquina universal de ensaios da marca EMIC, linha DL, com capacidade máxima de $100 \mathrm{kN}$ e célula de carga de $200 \mathrm{kgf}$.

A amostra de argamassa foi moldada sobre uma placa de aço inoxidável de $20 \mathrm{~cm}$ de diâmetro e que na parte inferior tem uma geometria adequada para ser encaixada na base da prensa. Também foi utilizado um gabarito de material plástico, para garantir a centralização da amostra no prato de aço, e um anel de PVC como molde. A Figura 7 mostra as ferramentas necessárias para a moldagem das amostras de acordo com Cardoso et al. [26].

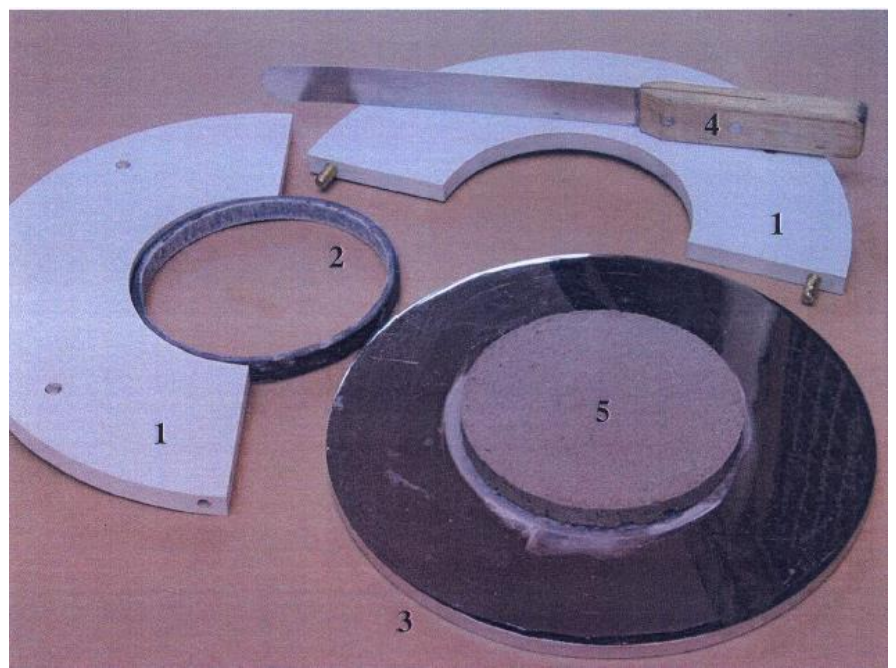

Figura 7: Ferramentas para moldagem das amostras para o ensaio de squeeze flow. (1) Gabarito; (2) Anel de PVC para moldagem; (3) Placa inferior; (4) Espátula; (5) Amostra moldada [26].

Algumas adaptações foram feitas no ensaio para este estudo, considerando-se algumas condições específicas da argamassa de reparo. $\mathrm{O}$ anel de PVC foi mantido durante o ensaio devido à fluidez apresentada pelo traço de referência da argamassa, tendo em vista que a baixa consistência da argamassa impedia a amostra de manter sua forma circular para a execução do ensaio e assim garantir a distribuição adequada dos esforços de compressão. Essa adaptação contribuiu também para simular de forma mais fiel as reais condições de aplicação de uma argamassa de reparo, ou seja, enclausurada pela estrutura e outros acessórios, como, por exemplo, a cavidade do reparo. Também foi escolhida a placa superior de 2" de diâmetro, que se deslocou a uma taxa de $0,1 \mathrm{~mm} / \mathrm{s}$ e possibilitou a aplicação de esforço de compressão sobre a argamassa restringida, simulando dessa forma o adensamento da argamassa de reparo, que tem uma aplicação característica manual, realizado com os dedos e a palma da mão do operário.

Foram ensaiadas três amostras de cada traço, das quais a curva média representa o resultado do ensaio, que está ilustrado na Figura 8. 


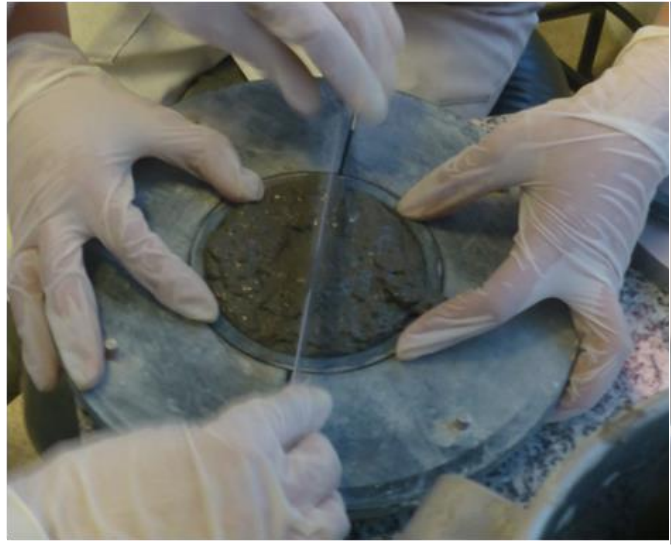

(a) Moldagem

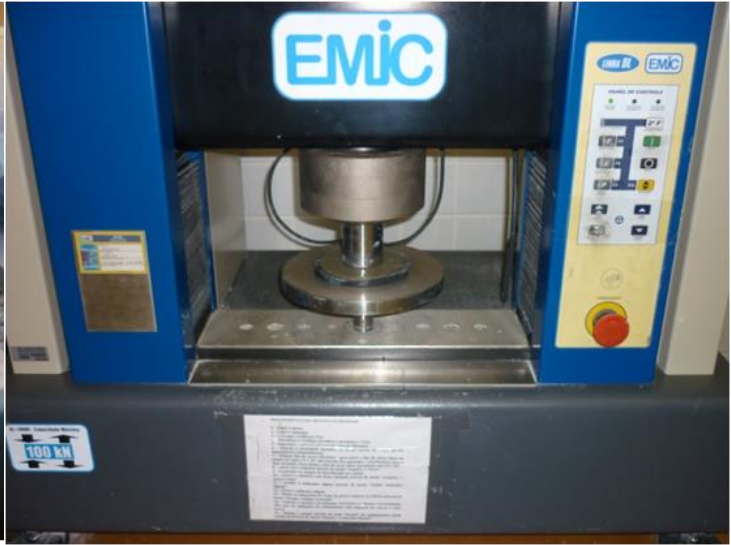

(b) Ensaio em andamento

Figura 8: Moldagem e ensaio de squeeze flow em andamento na máquina universal de ensaios.

De acordo com Cardoso et al. [26], para a interpretação do gráfico obtido pelo ensaio de squeeze Flow, normalmente são observadas três regiões bem definidas, como mostra a Figura 9.

No estágio I, o material se comporta como um sólido, sofrendo deformação elástica.

No estágio II, com um deslocamento intermediário, onde a deformação é plástica e/ou fluxo viscosa. Nesta etapa o material pode sofrer grandes deformações sem aumento significativo da força necessária para o deslocamento.

Já o estágio III, há um aumento significativo da força para manter as grandes deformações. Nessa etapa há a aproximação das partículas ou de outros constituintes, causando maior interação entre esses elementos, isso faz com que predomine a força de atrito, e com isso acontece o enrijecimento por deformação.

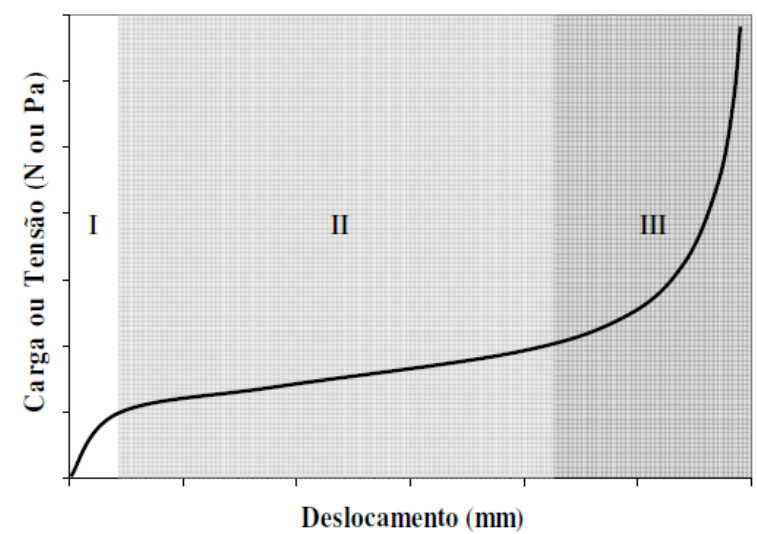

Figura 9: Perfil típico de carga vs. deslocamento de um ensaio de squeeze flow [26] .

\subsection{Ensaio de Flow Table}

Este ensaio seguiu os procedimentos da NBR 13276/2005 [27] e foi realizado para determinar o espalhamento da argamassa, sendo uma medida de sua fluidez submetida a impactos da mesa. O procedimento consiste em preencher com argamassa um molde metálico em forma de tronco de cone que está centralizado em uma mesa própria para o ensaio. Após o arrasamento, se retira o molde tronco cônico no sentido vertical e a manivela da mesa é acionada para determinar o índice de consistência, de maneira que a mesa suba e caia trinta vezes em 30 segundos.

Após a última queda da mesa, executou-se a medida do diâmetro da argamassa espalhada na mesa em três pontos distintos. A média dessas medidas é o índice de consistência da argamassa e quanto maior o valor, mais fluido o material em teste.

\subsection{Ensaio de Funil de Marsh}

O ensaio de Funil de Marsh foi realizado em pasta de cimento para complementar o estudo sobre a influência dos nanotubos de carbono na consistência de compósitos cimentícios.

Para a realização do ensaio, foram misturados os materiais secos na argamassadeira durante 2 minutos e depois se adicionou a solução de NTCs dispersos em água e aditivo. 
Este ensaio foi conduzido colocando um litro da pasta no funil que tem sua extremidade de saída fechada e abaixo um Becker. Quando a passagem da pasta é liberada e atinge o fundo do Becker, um cronômetro é acionado para determinar quanto tempo leva para preencher $500 \mathrm{ml}$ da pasta no Becker, Figura 10. Esse tempo é um indicativo de fluidez e serviu para estudar o efeito da variação do teor de NTC na consistência da pasta de cimento Portland, quanto maior o tempo de fluxo, menos fluida é a pasta.

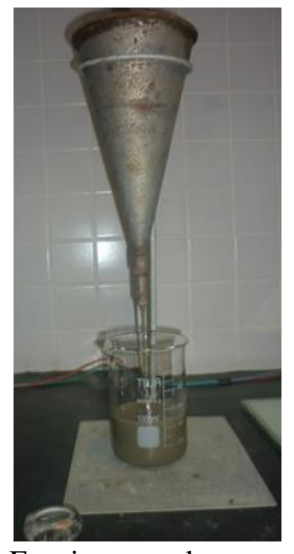

Ensaio em andamento

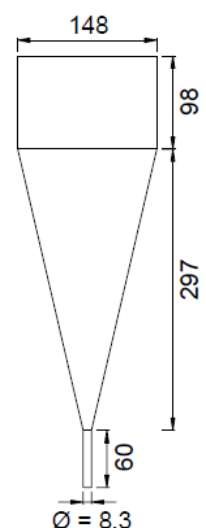

Esquema com dimensões

Figura 10: Ensaio do Funil de Marsh em andamento.

\subsection{Ensaio de Miniabatimento}

Assim como o ensaio do Funil de Marsh, o ensaio do miniabatimento foi realizado em pasta de cimento para complementar os ensaios de squeeze flow e flow table, também sendo um ensaio realizado em pastas e indicativo da sua fluidez.

A pasta foi colocada em um molde metálico em forma de tronco de cone, posicionado sobre o centro de um tampo de vidro que tem marcações de círculos distantes de 10 milímetros, Figura 11 . O interior deste recipiente tem formato de um tronco de cone e o seu peso evita que a pasta escoe por baixo. As dimensões do molde são: $57 \mathrm{~mm}$ de altura, $19 \mathrm{~mm}$ de diâmetro superior e $38 \mathrm{~mm}$ de diâmetro inferior.

Após o preenchimento com a pasta, a abertura superior é arrasada e o recipiente é retirado no sentido vertical para que a pasta se espalhe de forma uniforme na horizontal. O resultado do ensaio é a média de duas medidas perpendiculares de diâmetro na pasta espalhada. A Figura 11 mostra um exemplo de pasta após o seu espalhamento.

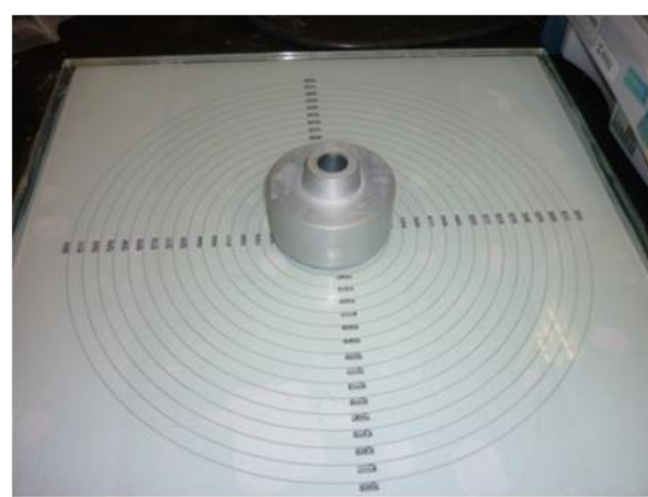

Placa de vidro com graduação e molde

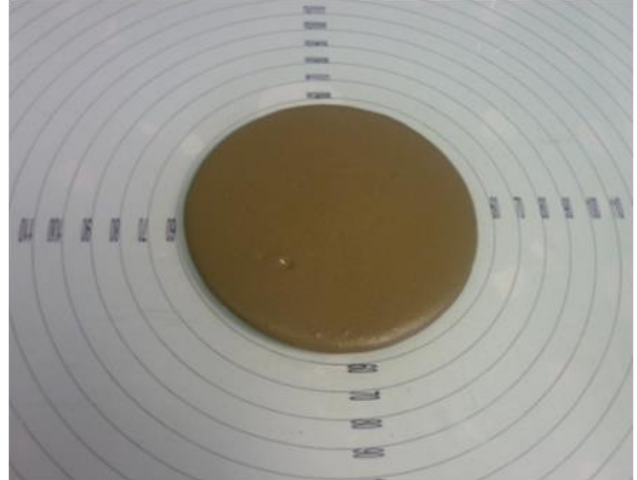

Pasta após a retirada do molde

Figura 11: Molde metálico e a placa de vidro com marcação usados no ensaio de miniabatimento e exemplo de pasta após o espalhamento.

\section{RESULTADOS E DISCUSSÕES}

\subsection{Resistência à compressão}

Os resultados do ensaio de resistência à compressão das argamassas com adição dos NTCs estão apresenta- 
dos na Figura 12, cujos dados se referem a 28 dias de cura submersa. Deve-se notar que, comparando com a série de referência, houve elevação da resistência à compressão em praticamente todos os casos de estudo. Neste caso, a exceção foi o teor de $0,5 \%$, que indicou resistência estatisticamente semelhante à série de referência e o motivo desta ocorrência se deve ao fato de que este nível de adição de NTC comprometeu a fluidez de forma a dificultar o adensamento dos corpos de prova. O teor de 0,40\% de NTC foi o que mais elevou a resistência à compressão, representando $27 \%$ de aumento em relação à série sem adição de NTC. Esta tendência de elevação da resistência à compressão com a incorporação de NTC está de acordo com outros trabalhos, como os de e Marcondes [12], Melo [13], Chaipanich et al. [14], Makar et al. [15]. O teste de Tukey foi usado como meio para identificar se as médias dos valores com NTCs são diferentes da série de referência.

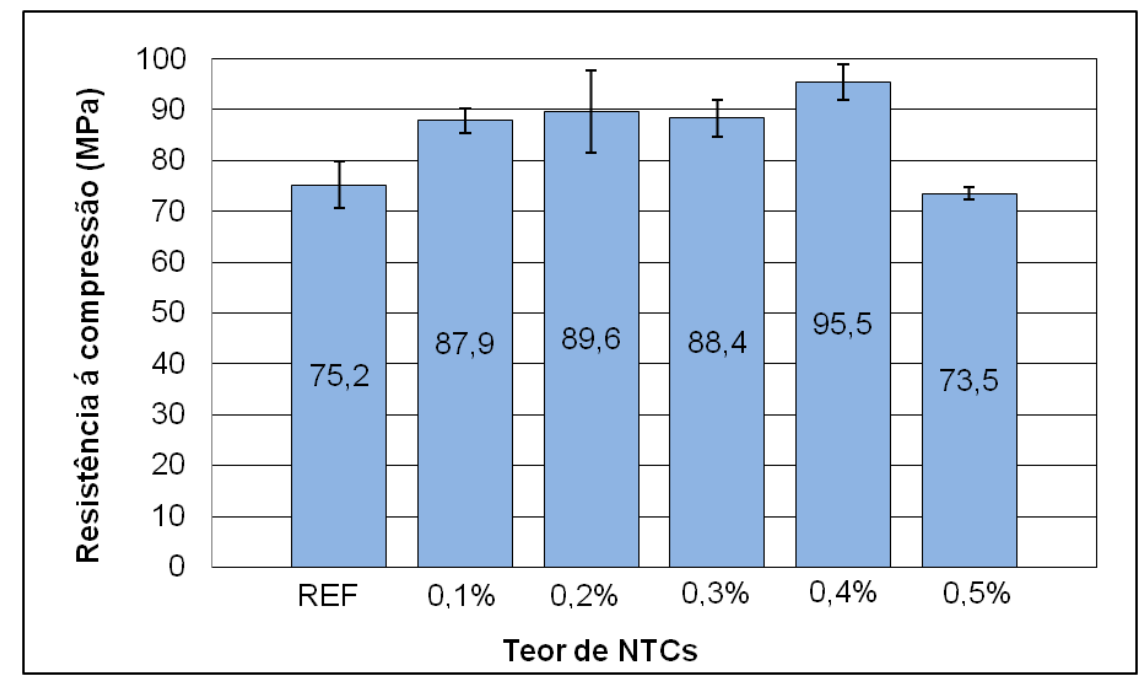

Figura 12: Resistência à compressão aos 28 dias de argamassa com adição de NTCs.

\subsection{Squeeze Flow}

A Figura 13 mostra o resultado do ensaio de squeeze flow para a série de referência e para as demais argamassas com os diferentes teores de NTC deste estudo.

O traço que não tem a adição de NTCs, denominado referência, não apresentou o primeiro estágio (deformação elástica), que caracteriza comportamento de um material sólido. Porém, o estágio de deformação plástica, que é o trecho da curva quase na horizontal, e o estágio III, onde é necessário um aumento da força para se manter as deformações (trecho mais vertical), ficaram bem definidos. Isso se deve ao fato de a argamassa apresentar alta fluidez. Apesar disso, vale salientar que estas argamassas não apresentaram indícios de separação de fases, se mantendo homogêneas ao longo dos ensaios.

Algumas curvas apresentam um trecho com ruídos, isso se deve a acomodação dos grãos com a aplicação do deslocamento, que acontece no instante que a deformação passa da fase plástica para o enrijecimento por deformação. Este tipo de comportamento também foi encontrado por Cardoso et al. [28] e Pereira [29] usando o mesmo procedimento de ensaio.

Para as argamassas que tiveram a adição de NTCs, os teores de $0,1 \%$ e $0,2 \%$ apresentaram o comportamento semelhante ao da argamassa referência, com grande parte da deformação passando pelo estágio plástico e atingindo em seguida o enrijecimento por deformação. A argamassa com teor de $0,3 \%$ foi a única a passar de forma clara pelos três estágios, deformação elástica, deformação plástica e enrijecimento por deformação. As curvas dos teores de $0,4 \%$ e $0,5 \%$ seriam quase paralelas se não fosse o fato do teor de $0,4 \%$ passar sucintamente pela deformação plástica, enquanto o teor de $0,5 \%$ sai do estágio inicial direto para o enrijecimento por deformação. Isso indica a elevada consistência do compósito de cimento Portland com $0,5 \%$ de NTC, que pode ter sido a causa da redução da resistência à compressão, resultante do comprometimento do adensamento no momento da moldagem dos corpos de prova. Esse comportamento leva a crer que esse teor de NTC é excessivo para a argamassa de reparo, pois comprometerá a sua aplicação.

Os dados de squeeze flow foram importantes para mensurar a influência dos teores de NTCs no perfil reológico das argamassas. De um modo geral, o resultado indica que a adição de NTC modifica o perfil reológico da argamassa, evidenciando que quanto maior o teor de NTC, menos fluida será a argamassa. O ensaio contribui principalmente para indicar os limites de teores de NTC de forma a se obter uma argamassa de reparo mais plástica, ou seja, com maior facilidade de aplicação visto que o adensamento dessa argamassa é feito manualmente e essa condição de plasticidade se torna fundamental. Teores até $0,3 \%$ de NTC poderiam ser considerados aceitáveis para a formulação da argamassa de reparo considerada nesse estudo. Os teores de 
0,4 e 0,5\% determinariam dificuldades de aplicação da argamassa. Esta constatação está de acordo com trabalhos prévios de Marcondes [12] e Melo [13], que citam o teor de 0,3\% de NTC em relação a massa de cimento como um teor ótimo.

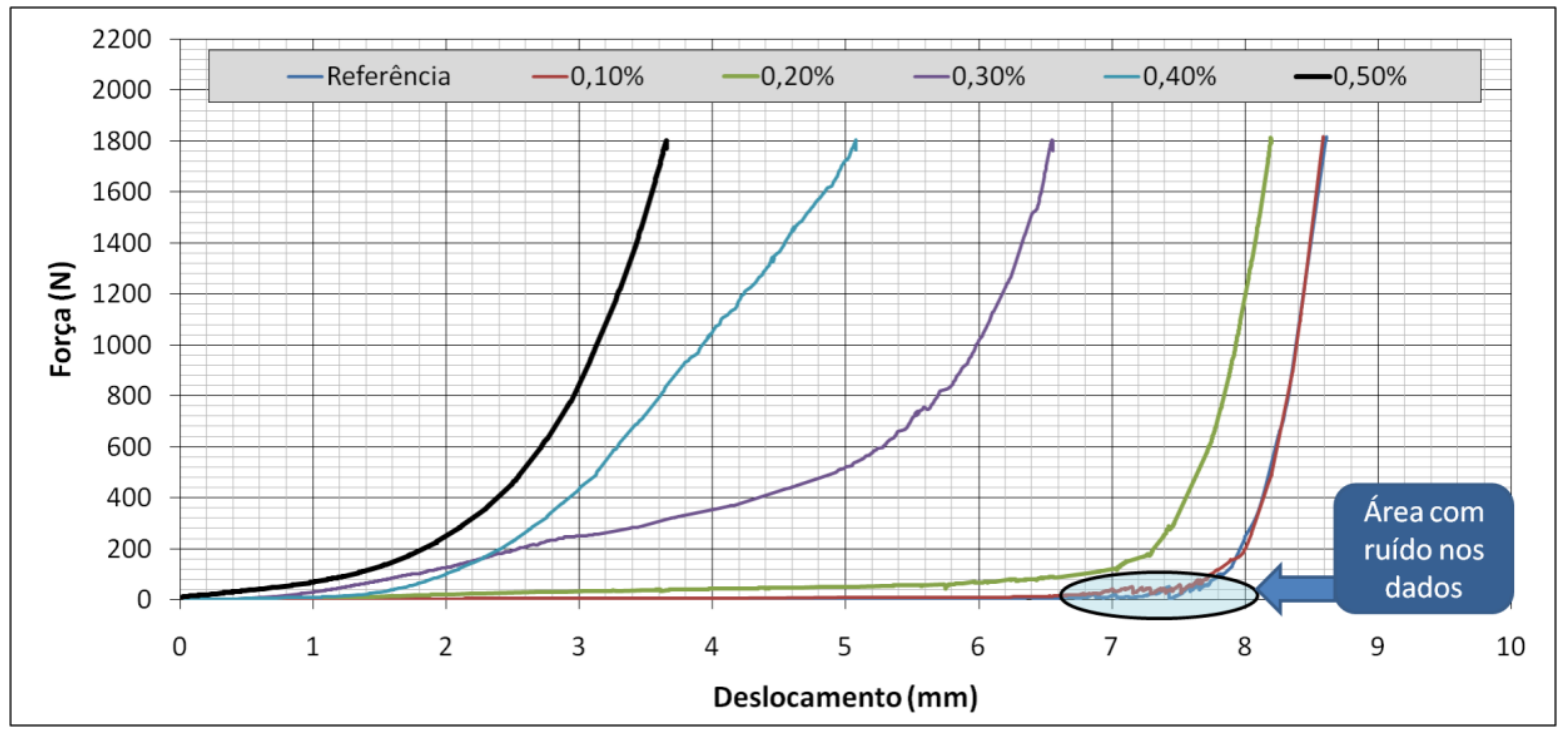

Figura13: Resultado do ensaio de squeeze flow para as argamassas com adição de NTCs.

Outro tipo de interpretação do ensaio de squeeze flow é usando a tensão de escoamento do material, que pode ser determinada pelos perfis reológicos da Figura 13. A determinação da tensão de escoamento se refere ao valor da tensão em que ocorre a transição do estágio I para o estágio II. A transição entre os dois estágios é definida pelo cruzamento de extrapolações lineares, como indicado por Cardoso et al. [ $\underline{30}$ ]. A Tabela 8 indica a tensão de escoamento de cada uma das argamassas testadas e evidencia que até $0,2 \%$ de NTC, em relação á massa de cimento, a tensão de escoamento é nula, apresentando valores progressivos a partir do teor de $0,3 \%$.

Desse modo, as argamassas de referência e as com teores de $0,1 \%$ e $0,2 \%$ de NTC, não apresentaram tensão de escoamento a partir das curvas, significando que o material se deforma apenas com o peso próprio. As argamassas com teores de 0,3\%,0,4\% e 0,5\% de NTC apresentaram tensão de escoamento, sendo então necessário aplicar uma determinada carga para iniciar seu escoamento da argamassa.

Tabela 8: Tensão de escoamento calculada de acordo com Cardoso et al. [리].

\begin{tabular}{c|c}
\hline $\begin{array}{c}\text { Teor de NTC (\%) - em relação à massa } \\
\text { de cimento }\end{array}$ & $\begin{array}{c}\text { Tensão de Escoa- } \\
\text { mento (PA) }\end{array}$ \\
\hline 0 (referência) & 0 \\
\hline 0,1 & 0 \\
\hline 0,2 & 0 \\
\hline 0,3 & 345 \\
\hline 0,4 & 490 \\
\hline 0,5 & 5180 \\
\hline
\end{tabular}

\subsection{Espalhamento no Flow Table e temperatura}

A Figura 14 mostra a temperatura ambiente e a temperatura da argamassa medida logo após a mistura na argamassadeira. Verifica-se que a temperatura do ambiente de laboratório ficou relativamente constante. Porém, é nítido que a adição de NTC causou uma elevação do calor de hidratação, com cerca de $5{ }^{\circ} \mathrm{C}$ e $6{ }^{\circ} \mathrm{C}$ de gradiente de elevação de temperatura no caso da adição de $0,4 \%$ e $0,5 \%$ de NTC, respectivamente.

Esta elevação de temperatura provavelmente está relacionada à capacidade dos NTCs de nuclear a reação de hidratação dos aglomerantes, como Melo [13] afirma que as nanopartículas agem como agentes de nucleação. E como relatado por Wang et al. [31], que pode haver a formação de uma rede condutora de energia, que ocorre quando os NTCs se conectam. 
MEDEIROS, M. H. F.; DRANKA, F.; MATTANA, A. J.; COSTA, M. R. M. M. revista Matéria, v.20, n.1, pp. 127 - 144, 2015.

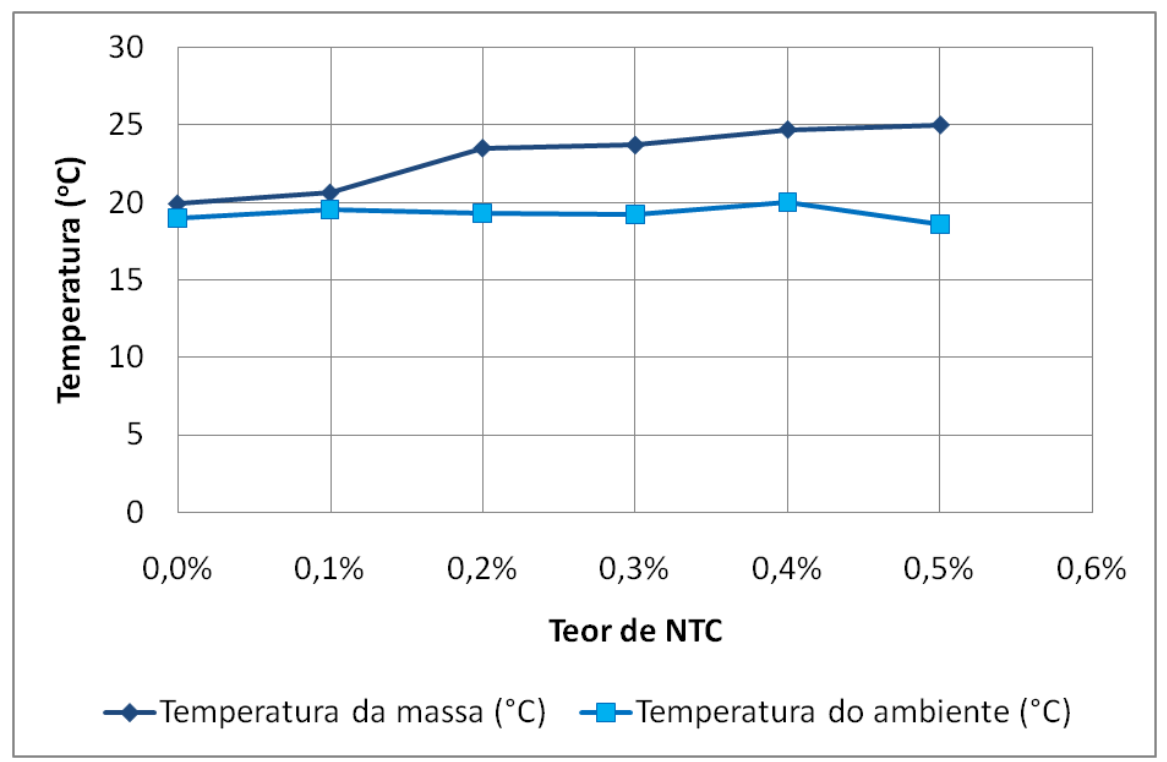

Figura 14: Elevação da temperatura causada pela adição de NTC.

A Figura 15 mostra que quanto maior o teor de NTCs, maior a consistência da argamassa, indicando que para manter uma dada fluidez necessária para uma determinada aplicação, a introdução do NTC requer o acréscimo de água ou aditivo superplastificante na argamassa. A elevação da consistência da argamassa provocada pela adição de NTCs no compósito de cimento Portland se deve a sua área específica elevadíssima, que tende a consumir água para adsorver na superfície das partículas de NTC. Para ter ideia de tal efeito, basta comparar a área específica do cimento $\left( \pm 0,4 \mathrm{~m}^{2} / \mathrm{g}\right)$, da sílica ativa $\left(19 \mathrm{~m}^{2} / \mathrm{g}\right)$ e do NTC $\left( \pm 250 \mathrm{~m}^{2} / \mathrm{g}\right)$. Tal diferença se reflete na elevação da necessidade de consumo de água para molhar a superfície dos sólidos da dispersão de partículas que é a argamassa ou pasta.

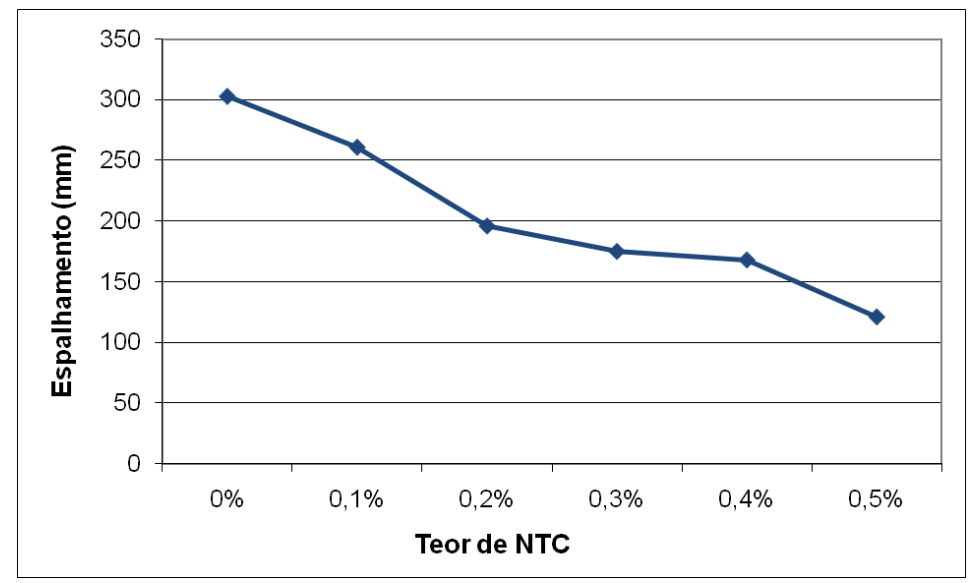

Figura 15: Influência do teor de NTC na redução do espalhamento no ensaio da mesa de consistência (flow table).

\subsection{Capacidade de fluir no Funil de Marsh}

Como mencionado anteriormente, este ensaio foi realizado em pasta de cimento, o mesmo traço da argamassa sem adicionar a areia.

Os resultados se encontram na Figura 16 e confirmam que o aumento do teor de NTC torna o compósito de cimento Portland menos fluido. 


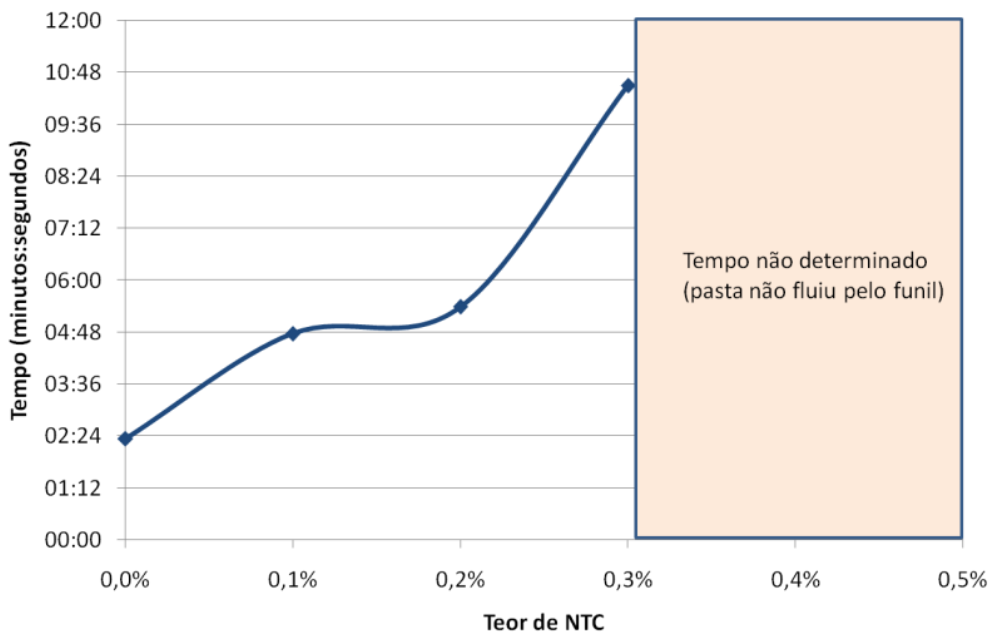

Figura 16: Resultados do ensaio de fluidez pelo Funil de Marsh com a elevação do teor de NTC.

O tempo para os teores de $0,4 \%$ e $0,5 \%$ não foram possíveis de serem cronometrados devido a falta de fluidez da pasta, que impossibilitou o preenchimento de $500 \mathrm{ml}$ de pasta no Becker para esses teores. A Figura 17 mostra o ponto em que a pasta parou de escorrer nos dois teores. Assim como no ensaio de squeeze flow, os dados do funil de Marsh indicam que aparentemente os NTCs devem ser usados até 0,3\% em relação à massa de cimento, corroborando com as indicações de Marcondes [12] e Melo [13].

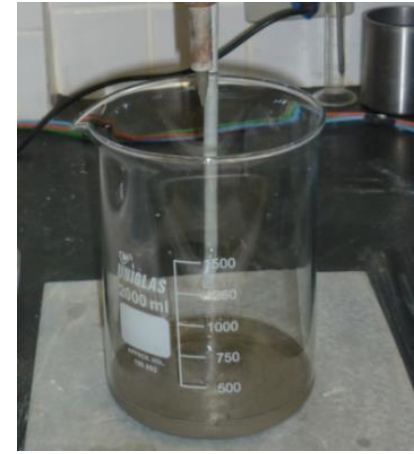

(a) Pasta de cimento com $0,4 \%$ de NTC

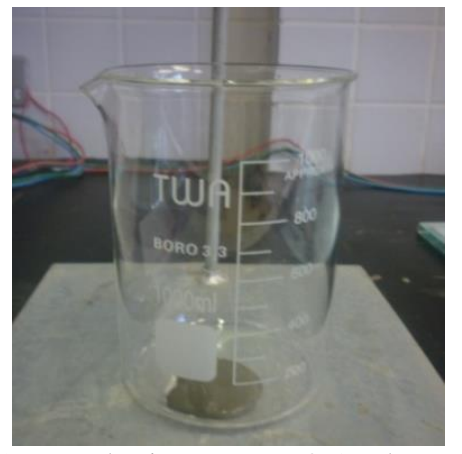

(b) Pasta de cimento com $0,5 \%$ de NTC

Figura 17: Momento em que a pasta de cimento parou de escorrer durante o ensaio de Funil de Marsh para os teores de (a) $0,4 \%$ e (b) $0,5 \%$ de NTC.

\subsection{Ensaio de Miniabatimento}

Os resultados do ensaio de miniabatimento estão apresentados na Figura 18. Pode-se observar que com a adição dos NTCs à pasta de cimento, o espalhamento diminui de forma proporcional e o resultado está coerente com os encontrados em todos os ensaios de medida das propriedades no estado fresco. Novamente o efeito de água consumida devido a elevada área de superfície das partículas de nanotubos de carbono. 


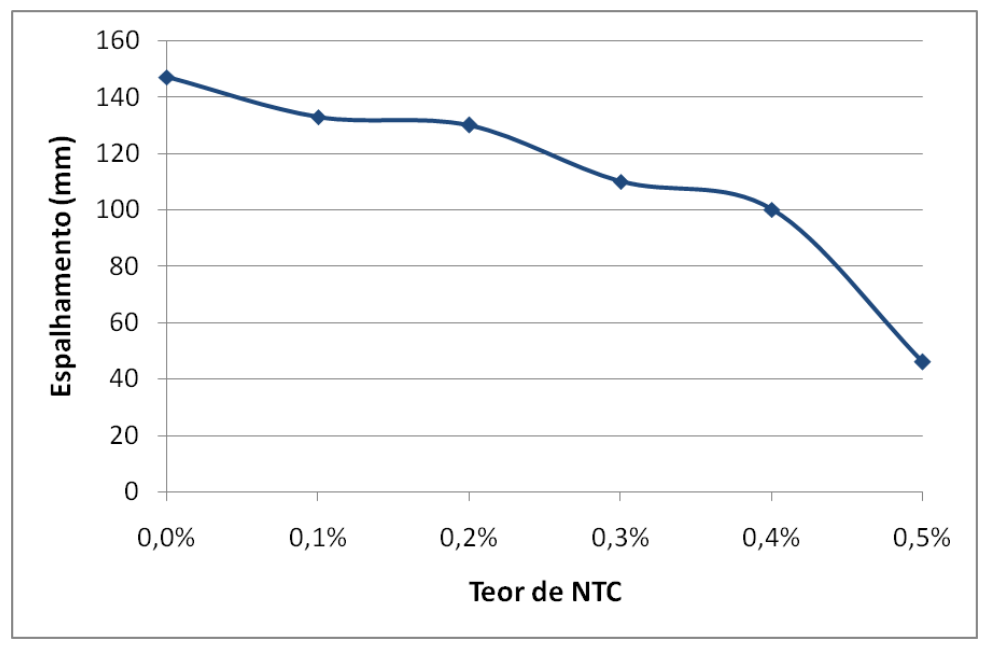

Figura18: Espalhamento no ensaio de miniabatimento em pasta de cimento com adição de NTC.

\section{CONCLUSÕES}

Esse estudo mostrou que a adição de nanotubos de carbono resulta em alterações na resistência à compressão e nas propriedades reológicas de argamassas de alta resistência.

As argamassas com adição de NTCs apresentaram acréscimo na resistência à compressão aos 28 dias de idade, porém, os resultados não seguiram uma tendência linear. Relacionando o teor de adição de NTCs com a resistência, ficou evidente que o teor de adição de $0,5 \%$ de NTC travou a massa e comprometeu o adensamento dos corpos de prova de resistência à compressão. Este foi o motivo de este teor de adição não ter resultado na elevação da resistência à compressão, se comparado com a série de referência.

Também foi comprovada a elevação da temperatura logo após a mistura da argamassa, sendo um indicativo de que a adição de NTC atua como agente de nucleação das reações de hidratação do cimento Portland, como relatado por Melo [13] e Wang et al. [31].

Nos ensaios para avaliar a consistência das pastas e argamassas, foi observado que a fluidez diminui de forma proporcional à adição dos NTCs. No caso das argamassas, o perfil reológico se modificou de forma mais insinuada a partir do teor de $0,3 \%$, onde os três estágios (deformação elástica, plástica e enrijecimento por deformação) aparecem de forma clara. Em todos os teores, o enrijecimento por deformação está presente, mas nos teores menores a deformação plástica é predominante, enquanto nos teores mais altos a deformação é pelo enrijecimento da argamassa.

A redução de fluidez das argamassas e pastas estudadas foi claramente provocada pela elevada área de superfície específica que o nanotubo de carbono tem como característica inerente. O cimento Portland ARI empregado nesta pesquisa tem área específica de $\pm 0,4 \mathrm{~m}^{2} / \mathrm{g}$, a sílica ativa de $19 \mathrm{~m}^{2} / \mathrm{g}$ e o NTC de $\pm 250 \mathrm{~m}^{2} / \mathrm{g}$. A introdução de um pó tão fino como o NTC no sistema de dispersão que é uma pasta ou argamassa afeta totalmente a fluidez devido a necessidade de água a ser adsorvida na superfície das partículas, faltando água para promover o escorregamento de partículas necessário para o comportamento de fluidez do sistema.

A escolha da argamassa para reabilitação estrutural é um processo muito criterioso, onde envolve diversos fatores que precisam ser analisados. Mas considerando as propriedades que foram ensaiadas (a resistência à compressão e propriedades reológicas), as argamassas com teores mais baixos $(0,1$ a $0,3 \%$ em relação a massa de cimento) de adição de NTCs podem ser usadas como graute, pois têm consistência fluida e atingem altas resistências iniciais e finais, que como indicado por Tula et al. [32] são características importantes aos grautes para reparos de estruturas de concreto armado.

É importante salientar que as constatações deste trabalho valem para os materiais utilizados nesta pesquisa. Isso é importante de ser destacado porque os NTCs estão ainda sendo investigados como campo de pesquisa e as variações no seu processo de produção podem gerar mudanças na sua influência como adição em compósitos de cimento Portland.

\section{AGRADECIMENTOS}

A equipe agradece ao apoio da Universidade Federal do Paraná (UFPR) por possibilitar o empenho de seus professores/pesquisadores e colocar a sua infraestrutura à disposição deste trabalho de pesquisa. Além disso, deve-se registrar o agradecimento pela concessão de bolsas de estudo promovidas pela Coordenação de Aperfeiçoamento de Pessoal de Nível Superior (CAPES) e Conselho Nacional de Desenvolvimento Científico e Tecnológico $(\mathrm{CNPq})$. 


\section{BIBLIOGRAFIA}

[1] SANCHEZ, F., SOBOLEV, K., "Nanotechnology in concrete - A review", Construction and Building Materials, v. 24, n. 11, pp. 2060-2071, 2010.

[2] SOBOLEV, K., FERRADA, G.,"How nanotechnology can change the concrete world: Part 1", Am. Ceram. Soc. Bull, v. 84, n. 10, pp. 7-14, 2005.

[3] ATZENI, C., MASSIDDA, L. SANNA, U., "Dimensional variations, capillary absorption and freezethaw resistance of repair mortars admixed with polymers", Cement and Concrete Research, v. 23, n. 2, pp. 301-308, 1993.

[4] HASSAN, K.E., BROOKS, J.J., AL-ALAWI, L., "Compatibility of repair mortars with concrete in a hotdry environment", Cement and Concrete Composites, v. 23, n. 1, pp. 93-101, 2001.

[5] MIRZA, J., MIRZA, M.S., LAPOINTE, R., "Laboratory and field performance of polymer-modified cement-based repair mortars in cold climates", Construction and Building Materials, v. 16, n. 6, pp. 365-374, 2002.

[6] MEDEIROS, M.H.F., HELENE, P., SELMO, S.M.S., "Influence of EVA and acrylate polymers on some mechanical properties of cementitious repair mortars", Construction and Building Materials, v. 23, n. 7, pp. 2527-2533, 2009.

[7] RAMLI, M., TABASSI, A.A., HOE, K.W., "Porosity, pore structure and water absorption of polymermodified mortars: An experimental study under different curing conditions", Composites Part B: Engineering, v. 55, pp. 221-233, 2013.

[8] MA, H., LI, Z., "Microstructures and mechanical properties of polymer modified mortars under distinct mechanisms", Construction and Building Materials, v. 47, pp. 579-587, 2013.

[9] MEDEIROS, M.H.F., Estruturas de concreto armado com corrosão de armaduras causada por carbonatação: Estudo comparativo de argamassas de reparo quanto à proteção do aço, Dissertação de M. Sc., Programa de Pós-graduação em Engenharia Civil e Urbana, Universidade de São Paulo, São Paulo, Brasil, 2002.

[10] RAMLI, M., TABASSI, A.A., "Effects of Different Curing Regimes on Engineering Properties of Polymer-Modified Mortar”, Journal of Materials in Civil Engineering, v. 24, n. 4, pp. 468-478, 2012.

[11] RIBEIRO, J.L.S., PANOSSIAN, Z., SELMO, A.M.S., "Proposed criterion to assess the electrochemical behavior of carbon steel reinforcements under corrosion in carbonated concrete structures after patch repairs", Construction and Building Materials, v. 40, pp. 40-49, 2013.

[12] MARCONDES, C.G.N., Adição de nanotubos de carbono em concretos de cimento Portland - absorção, permeabilidade, penetração de cloretos e propriedades mecânicas, Dissertação de M. Sc., Programa de Pós-graduação em Engenharia de Construção Civil - PPGECC/UFPR, Universidade Federal do Paraná, Curitiba, Brasil, 2012.

[13] MELO, V.S., Nanotecnologia aplicada ao concreto: efeito da mistura física de nanotubos de carbono em matrizes de cimento Portland, Dissertação de M.Sc., Universidade Federal de Minas Gerais, Belo Horizonte, 2009.

[14] CHAIPANICH, A., NOCHAIYA, T., WONGKEO, W., et al., "Compressive strength and microsture of carbon nanotubes-fly ash cement composites", Materials Science and Engeneering: A, v. 527, n. 4-5, pp. 1063-1067, 2010.

[15] MAKAR, J., MARGESON, J., LUH, J., "Carbon nanotube /cement composites - early results and potential applications", In: $3^{\circ}$ International Conference on Construction Materials: Performance, Innovations and Structural Implications, pp. 1-10, Vancouver, 2005.

[16] LI, H., XIAO, H.G., OU, J.P.,“A study on mechanical and pressure-sensitive properties of cement mortar with nanophase materials", Cement and Concrete Research, v. 34, n. 3, pp. 185-189, 2004.

[17] KOSHIO, A., YUDASAKA, M., ZHANG, M., et al., "A Simple Way to Chemically React Single-Wall Carbon Nanotubes with Organic Materials Using Ultrasonication”, Nano Letters, v. 1, n. 7, pp. 361-363, 2001.

[18] KONSTA-GDOUTOS, M.S., ZOI S, M., SURENDRA, P.S., "Highly dispersed carbon nanotube reinforced cement based materials", Cement and Concrete Research, v. 40, n. 7, pp. 1052-1059, 2010.

[19] MENDOZA, O., SIERRA, G., TOBON, J.L., "Influence of super plasticizer and $\mathrm{Ca}(\mathrm{OH})_{2}$ on the stability of functionalized multi-walled carbon nanotubes dispersions for cement composites applications", Construction and Building Materials, v. 47, pp. 771-778, 2013. 
[20] ASSOCIAÇÃO BRASILEIRA DE NORMAS TÉCNICAS. NBR 7211: Agregados para concreto - Especificação. Rio de Janeiro, 2009.

[21] BATISTON, E. R, HAMPINELLI, D., OLIVEIRA, R. C., et al., "Funcionalização e efeito da incorporação de nano tubos de carbono na cinética de hidratação em matrizes cimentícias", In: $52^{\circ}$ Congresso Brasileiro do Concreto, pp. 1-10, Fortaleza, 2010.

[22] MELO, V. S., CALIXTO, J. M., LADEIRA, L. O., et al., "Desempenho de argamassas de cimento Portland contendo nanotubos de carbono e aditivo de melamina", Construindo, v. 3, n. 2., pp. 21-26, 2011.

[23] HENCHE, D.P., Composto Cimentício de alta resistência com adição de nanotubos de carbono, Dissertação de M. Sc., Programa de Pós-graduação em Engenharia de Construção Civil - PPGECC/UFPR, Universidade Federal do Paraná, Curitiba, Brasil, 2013.

[24] ASSOCIAÇÃO BRASILEIRA DE NORMAS TÉCNICAS. NBR 7215: Cimento Portland - Determinação da resistência à compressão. Rio de Janeiro, 1997.

[25] ASSOCIAÇÃO BRASILEIRA DE NORMAS TÉCNICAS. NBR 15839: Argamassa de assentamento e revestimento de paredes e tetos - Caracterização reológica pelo método squeeze-flow. Rio de Janeiro, 2010.

[26] CARDOSO, F.A., JOHN, V.M., PILEGGI, R.G., "Squeze-flow aplicado a argamassas de revestimento: Manual de utilização", Boletim Técnico da Escola Politécnica da USP, v.1, pp. 1-29, 2010.

[27] ASSOCIAÇÃO BRASILEIRA DE NORMAS TÉCNICAS. NBR 13276: Argamassa para assentamento e revestimento de paredes e tetos - Preparo da mistura e determinação do índice de consistência. Rio de Janeiro, 2005.

[28] CARDOSO, F. A., PILEGGI, R. G., JOHN, V. M., "Caracterização reológica de argamassas pelo método de squeeze-Flow", In: VI Simpósio Brasileiro de Tecnologia de Argamassas e I International Symposiumon Mortars Technology, pp. 121-143, Florianópolis, 2005.

[29] PEREIRA, E., Estudo da influência das propriedades de argamassas colantes na aderência de revestimentos cerâmicos aplicados no assentamento de piso sobre piso, Dissertação de M. Sc., Programa de Pósgraduação em Engenharia de Construção Civil, Universidade Federal do Paraná, Curitiba, Paraná, Brasil, 2012.

[30] CARDOSO, F. A., JOHN, V. M., PILEGGI, R. G., "Rheological behavior of mortars under different squeezing rates", Cement and Concrete Research, v. 39, pp. 748-753, 2009.

[31] WANG, B., GUO, Z., HAN, Y., ZHANG, T., "Electromagnetic wave absorbing properties of multiwalled carbon nanotubes/cement composites", Construction and Building Materials, v. 46, pp. 98-103, 2013. [32] TULA, L., OLIVEIRA, P.S.F., OLIVEIRA, R.R., “Grautes”, Revista Téchne, v. 67, pp. 60-68, 2002. 